\title{
Comparison of hydrometer settling times in soil particle size analysis
}

\author{
CAROLYN C. BOHN AND KARL GEBHARDT
}

\begin{abstract}
Although soil texture is important to plant growth, cultivation, hydraulic conductivity, and soil strength, laboratory procedures for determining particle size distribution can be confusing. A number of settling times have been proposed for the hydrometer method used to analyze the fine earth fraction of soils. To separate sand and silt, hydrometer readings at 30 and 60 seconds, 35 seconds, or at $\mathbf{4 0}$ seconds have been recommended. To distinguish between silt and clay, recommendations have been made for readings at 6-8 hours and 12-15 hours, 1.5 and 24 hours, 2 and 24 hours or at 8 hours. In this study, no significant differences in estimates of sand content were found between readings made at 30 and 60 seconds and at $\mathbf{4 0}$ seconds. However, estimates from readings on both sides of the silt-clay separation (at 6 hours and 12 hours) showed a significant variation of clay content within the sample probably due to an inadequate method of splitting the soil samples into subsamples. Clay estimates from 2-hours readings differed significantly from the average estimate of the split sample 6/12hours readings. Numerical differences were seen among particle size estimates from various methods; if the soll texture is near a division between 2 classes, these differences may result in different textures being assigned.
\end{abstract}

Key Words: particle size distribution analysis, soil texture, soll analysis methods

Senior author is hydrologist, U.S. Forest Service, Intermountain Research Station, Boise, Idaho 83705 . Previously, lab research associate, Dept. of Range, Wildlife and

Forestry, University of Nevada, Reno; junior author is hydrologist, Bureau of Land Management, State Office, Boise, Idaho 83706.

Research was funded by the United States Department of the Interior, Bureau of Land Management, Saval Ranch Research and Evaluation Project. University of Nevada Agricultural Experiment Station Project 665. The authors thank Shirley

Hudson for statistical advice.

Manuscript aocepted 21 June 1988.
Soil scientists have long recognized the importance of soil texture to plant growth, cultivation, hydraulic conductivity and soil strength. However, managers preparing to determine soil texture are sometimes confused by conflicting procedural recommendations. Textural classes can be determined either in the field or by a laboratory particle size distribution analysis. The laboratory analysis most often available to land managers is some version of the hydrometer method first introduced by Bouyoucos (1927). Day (1965) and the American Society for Testing and Materials (A.S.T.M.) (1972) have detailed the procedure generally accepted by land management agencies and an updated edition was recently released (Gee and Bauder 1986). In this method, a measured amount of soil is suspended in water and the suspension density is determined with a specialized hydrometer. As soil particles settle, the suspension density decreases. Because larger particles settle faster, the particle size and summation percent remaining for that size can be calculated for each measurement time using the observed hydrometer level, and these results are graphed. From the relationship on the graph, the percent of a particular particle size class can be estimated (Day 1965).

The accuracy of the size class distribution estimate depends on a constant temperature, careful particle dispersal, and proper timing of the density observations. In the past, chemical dispersal has often been accomplished with a $5 \%$ Calgon (water softener trade name) solution. However, the preparation currently on the market may not contain phosphates, which are necessary for good dispersal; the label should be examined and a dispersing agent such as sodium hexametaphosphate purchased from a chemical supplier, if necessary. Phosphates are particularly important for soils high in 
salts or organic matter. While Day (1965) recommends soaking at least 10 minutes, the A.S.T.M. (1972) recommends several hours and the most recent laboratory procedures now specify soaking overnight (Gee and Bauder 1986). Likewise, the practice of using milkshake mixers for mechanical particle dispersal has been questioned (Doolittle 1957, Walker and Hutka 1973), but continues in many labs. It is generally thought that a reciprocal shaker is slow and gentle but may not break up cemented soils, while the mixer is fast and vigorous but may break down sands affected by weathering. Some of the problem may be avoided by making plastic mixing paddles. Regardless of what methods are selected for particle dispersal, the exact procedure should be described and used consistently.

The timing of the hydrometer readings depends on the size classification system being used. The separation between silt and clay used by the U.S.D.A. $(0.002 \mathrm{~mm})$, usually occurs between 8 to 12 hours of undisturbed settling, but the exact time cannot be identified beforehand. Measurements of the solution density at 6-8 hours and again at 12-15 hours will yield data which brackets the actual time at which all the silt size particles have settled and therefore brackets the corresponding percent clay on the particle size-summation percentage graph. Similarly, the break between sand and silt $(0.05 \mathrm{~mm})$ occurs between 30 to 60 seconds of settling time and can be estimated from a graph showing these data points.

In order to reduce laboratory time, researchers have proposed a variety of observation times which approximate the desired particle size and depend on extrapolation rather than surrounding the size with measurements. Bouyoucos (1962) suggested that readings at 40 seconds and 2 hours were sufficient, but Gee and Bauder (1979) stated that 2 hours over-estimated the clay fraction and developed a method of weighted averages using 1.5 and 24 hours readings for the clay fraction. Patrick (1958) used 35 seconds and 8 hours. The methodology endorsed by the A.S.T.M., and generally accepted by land management agencies, uses readings at 30 seconds, 3, 10, and 30 minutes, and 1.5, 4.5, and 12 hours (Day 1965). However, A.S.T.M. (1972) also recommended 2, 5, 15 and 30 minutes, and 1,4 , and 24 hours, and the 2 nd edition of the standard methods manual (Gee and Bauder 1986) cites 30 and 60 seconds, 3, 10, and 30 minutes and 1, 1.5, 2, and 24 hours. To save lab time and expedite the analysis, some labs terminate the analysis at 6-8 hours. Although the best estimates would be expected from density observations which bracket the breakoff between size groups, in some cases, estimates from shorter settling times may suffice. It is important to identify what effect shorter settling times may have on soil texture estimations. We report here results from observations made at 30,40 , and 60 seconds and 2,6 , and 12 hours.

\section{Methods}

Twelve soil samples were collected from a 1,200 foot reach of streambank in the Independence Mountains, 50 miles north of Elko, Nevada. As is typically true, these riparian soils have not been classified to series, but are generally permeable alluvium. No effort was made to select a wide range of textures. A vertical cut was made into the streambank at each sample site and the samples were collected from the freshly exposed soils. The samples were oven-dried and sieved and the fraction passing the 2-mm sieve saved for analysis by the hydrometer method (Day 1965). Two subsamples from each sample were derived by gently inverting the original sample several times in a closed container and spooning out $\mathbf{4 0}$ grams for each subsample. Each subsample was then uniformly dispersed by soaking in $5 \%$ Calgon solution for 12 minutes followed by stirring for 5 minutes in a milkshake mixer. Each subsample was poured into a Bouyoucos tube, diluted with enough distilled water to bring the suspensions to $1,000 \mathrm{ml}$., and mixed with a plunger. The suspension density was read with an A.S.T.M.
$152 \mathrm{H}$ Soil Hydrometer at 30, 40, and 60 seconds, 2, 6, and 12 hours. Thus, data were collected to test 3 methods: (1) 30 and 60 seconds to sample either side of the sand/ silt division, and 6 and 12 hours to sample either side of the silt/clay division (the "bracketing" method); (2) 40 seconds and 6 hours to estimate both sand and clay separation points; (3) 40 seconds and 2 hours to estimate both sand and clay separation points. All readings were adjusted for temperature (Day 1965) and particle size diameters vs. summation percentages were graphed for each subsample to determine percentages for specific particle size groups.

The resulting sand and clay percentages were analyzed separately. Using the 12 samples as replications, paired T-tests $(n=12)$ were employed to test the sand estimates between: (1) the 2 subsamples each using the $30 / 60$ seconds bracket method; (2) $30 / 60$ seconds bracket vs. 40 seconds and 6 hours method; (3) $30 / 60$ seconds bracket $v s$. the 40 seconds and 2 hours method; (4) average of the two $30 / 60$ seconds bracket subsamples vs. 40 seconds and 6 hours; (5) average of the two $30 / 60$ seconds brackets vs. 40 seconds and 2 hours. Similarly, paired T-tests were employed to test the clay estimates between: (1) the 2 subsamples each using the $6 / 12$ hours bracket method; (2) 6/12 hours bracket method vs. the 6 hours and 40 seconds method; (3) 6/12 hours bracket vs. 2 hours and 40 seconds method; (4) average of the two $6 / 12$ hours bracket subsamples vs. 6 hours and 40 seconds; (5) average of the two $6 / 12$ hours brackets vs. 2 hours and $\mathbf{4 0}$ seconds method.

\section{Results}

The percentages of particle size classes are displayed in Tables 1 and 2. Percent sand estimates showed no significant differences

Table 1. Percent sand estimates.

\begin{tabular}{|c|c|c|c|c|c|}
\hline $30 / 60$ Seconds & $\begin{array}{c}\text { Bracketing M } \\
\text { Sub- } \\
\text { sample } \\
1\end{array}$ & $\begin{array}{l}\text { thod } \\
\text { Sub- } \\
\text { sample } \\
2\end{array}$ & $\begin{array}{l}\text { Average } \\
\text { of sub- } \\
\text { samples }\end{array}$ & $\begin{array}{c}40 \text { Sec. \& } \\
6 \\
\text { hours }\end{array}$ & $\begin{array}{c}40 \text { Sec. } \& \\
2 \\
\text { hours }\end{array}$ \\
\hline $\begin{array}{l}\text { Sample 1 } \\
\text { Sample } 2 \\
\text { Sample } 3 \\
\text { Sample } 4 \\
\text { Sample } 5 \\
\text { Sample } 6 \\
\text { Sample } 7 \\
\text { Sample } 8 \\
\text { Sample } 9 \\
\text { Sample } 10 \\
\text { Sample } 11 \\
\text { Sample } 12\end{array}$ & $\begin{array}{l}51.5 \\
54.0 \\
50.5 \\
48.0 \\
41.0 \\
44.0 \\
50.0 \\
57.0 \\
44.0 \\
75.0 \\
45.0 \\
43.5\end{array}$ & $\begin{array}{l}52.0 \\
54.5 \\
47.5 \\
49.5 \\
46.5 \\
47.0 \\
55.0 \\
59.5 \\
44.5 \\
78.0 \\
41.0 \\
44.0\end{array}$ & $\begin{array}{l}51.8 \\
54.3 \\
49.0 \\
48.8 \\
43.8 \\
45.5 \\
52.5 \\
58.3 \\
44.3 \\
76.5 \\
43.0 \\
43.8\end{array}$ & $\begin{array}{l}50.0 \\
52.5 \\
49.5 \\
50.0 \\
44.5 \\
47.0 \\
55.0 \\
59.5 \\
46.5 \\
76.5 \\
42.0 \\
44.0\end{array}$ & $\begin{array}{l}50.0 \\
52.5 \\
49.5 \\
50.0 \\
44.5 \\
47.0 \\
55.0 \\
59.5 \\
46.5 \\
76.5 \\
42.0 \\
44.0\end{array}$ \\
\hline
\end{tabular}

between any groups (Table 3). Because the sand/silt separation occurs within a very small time range, any reading between 30 and 60 seconds should be reasonably close to the actual break. Analysis of the clay groups showed a significant difference between the 2 sub-samples which are both estimated by the standard $6 / 12$ hours bracket method. This was apparently due to variability within the sample and the difficulty of adequately mixing and splitting soil samples into comparable subsamples. For these samples, the difference in clay estimates between the standard $6 / 12$ hours bracket method and the 6 hour method does not appear to be greater than the variability encountered in splitting the sample by hand. However, the 2 hours clay estimate differed significantly ( .01 level) from the average of the two 6/12 hours clay estimates, and from the unaveraged $6 / 12$ hours estimate at a lesser level of significance (.10). There were some noticeable numerical differences between the estimates from the 6/12 hours bracket method and both methods using shorter settling times, probably due to the distance 
Table 1. Percent clay eatimatea.

\begin{tabular}{lccccc}
\hline \hline 6/12 Seconds Bracketing Method & $\begin{array}{c}\text { Sub- } \\
\text { sample } \\
\end{array}$ & $\begin{array}{c}\text { Sub- } \\
\text { sample }\end{array}$ & $\begin{array}{c}\text { Average } \\
\text { of sub- } \\
\text { samples }\end{array}$ & $\begin{array}{c}\text { 40 Sec. \& } \\
\text { hours }\end{array}$ & $\begin{array}{c}40 \text { Sec. \& } \\
2\end{array}$ \\
& 1 & hours \\
\hline Sample 1 & 8.5 & 6.0 & 7.3 & 2.5 & 2.0 \\
Sample 2 & 10.5 & 7.5 & 9.0 & 6.0 & 3.0 \\
Sample 3 & 8.5 & 7.5 & 8.0 & 5.5 & 11.5 \\
Sample 4 & 10.5 & 5.0 & 7.8 & 2.5 & 2.0 \\
Sample 5 & 13.0 & 9.0 & 11.0 & 7.0 & 7.0 \\
Sample 6 & 12.0 & 9.0 & 10.5 & 7.5 & 4.5 \\
Sample 7 & 12.0 & 12.0 & 12.0 & 14.0 & 14.5 \\
Sample 8 & 10.5 & 9.0 & 9.8 & 19.0 & 6.0 \\
Sample 9 & 18.0 & 15.5 & 16.8 & 16.5 & 15.0 \\
Sample 10 & 6.0 & 6.0 & 6.0 & 6.0 & 5.0 \\
Sample 11 & 8.0 & 8.0 & 8.0 & 7.5 & 2.5 \\
Sample 12 & 10.5 & 9.5 & 10.0 & 7.5 & 7.0 \\
\hline
\end{tabular}

Table 3. T-values from paired comparisons of \% sand and \% clay extimutes by different methods $(\mathrm{d}=\mathbf{1 1})$.

\begin{tabular}{lll}
\hline \hline Particle size & \multicolumn{1}{c}{ Methods compared } & T-value \\
\hline Sand & $30 / 60$ sec bracket vs. $30 / 60$ sec & 1.5844 \\
Sand & $30 / 60$ sec bracket vs 40 sec \& 6 hours & 0.3978 \\
Sand & Average bracketing vs. 40 sec \& 6 hours & 1.1010 \\
Sand & $30 / 60$ sec bracket vs. 40 sec \& 2 hours & 0.3978 \\
Sand & Average bracketing vs. 40 sec \& 2 hours & 1.1010 \\
Clay & 6/12 hour bracket vs. 6/12 hour bracket & $4.0000^{* *}$ \\
Clay & 6/12 hour bracket vs. 40 sec \& 6 hours & 0.2025 \\
Clay & Average bracketing vs. 40 sec \& 6 hours & 1.0814 \\
Clay & 6/12 hour bracket vs. 40 sec \& 2 hours & $2.1454^{*}$ \\
Clay & Average bracketing vs. 40 sec. \& 2 hours & $3.2035^{* *}$ \\
\hline
\end{tabular}

* Significant difference at .01 level

- Significant difference at .10 level of extrapolation over the graph. Because readings at 6 and 12 hours bracket the actual silt/ clay break, that method, in theory, provides the more accurate estimates. Where the textural classification is borderline, even small numerical differences may change the class; this occurred with 2 samples.

\section{Conclusions}

Hydrometer readings anywhere between 30 and 60 seconds should reasonably estimate the percent sand in a soil sample. However, the percent sand estimate generally is not a problem for scientists wanting to save lab time. The silt/clay separation requires several hours of settling time, although opinions vary on the number of hours needed. Because there was no statistical difference between the $6 / 12$ hours method which bracketed the silt/clay separation and the method which terminated at 6 hours, 6 hours of settling should be adequate, at least for some soils. However, the numerical differences observed between the 2 methods could occasionally define different textural classes, and the longer method theoretically provides the greatest accuracy. Care should be taken to thoroughly mix dry samples. The level of precision required will depend on the intended use of the data.

\section{Literature Cited}

American Society for Teating and Materials. 1972. Standard method for particle-size analysis of soils. Amer. Soc. Testing and Materials, D422-63 (reapproved 1972).

Bouyoucos, G. 1927. The hydrometer as a new method for the mechanical analysis of soils. Soil Sci. 23:343-352.

Bouyoucos, G. 1962. Hydrometer method improved for making particle size analysis of soils. Agron. J. 54:464-465.

Doolittle, W. 1957. Wear of soil mixer paddles and effect on mechanical analysis. Soil Sci. Soc. Amer. Proc. 21:662.

Day, P. 1965. Particle fractionation and particle-size analysis. In: Methods of Soil Analysis, Part 1, C.A. Black (ed), Number 9 Agronomy Series, Amer. Soc. of Agron., Inc., Madison, Wisc.

Gee, G.W., and J.W. Bauder. 1979. Particle size analysis by hydrometer: A simplified method for routine textural analysis and a sensitivity test of measurement parameters. Soil Sci. Soc. Amer. J. 43:1004-1007.

Gee, G.W., and J.W. Bauder. 1986. Particle size analysis p. 404-409. In: Methods of Soil Analysis, Part 1, A. Klute (ed), Agronomy No. 9, 2nd ed. Amer. Soc. of Agron., Inc., Soil Sci. Soc. of Amer. Madison, Wisc.

Patrick, W. 1958. Modification of method of particle size analysis. Soil Sci. Soc. Proc. 22:366-367.

Walker, P.H., and J. Hutka. 1973. Grain fragmentation in preparing samples for particle-size analysis. Soil Sci. Soc. Amer. Proc. 37:278-280. 